\title{
Evaluation of the Use of the Microwave System and Calculation of Economic Efficiency
}

\author{
Z. H. Aliyev \\ Department of Agriculture, Institute of Soil Science and Agrochemistry of ANAS, Baku-2019, Azerbaijan
}

Received: 10-07-2020; Revised: 20-08-2020; Accepted: 10-09-2020

\begin{abstract}
Cost-effectiveness calculations for computational irrigation options, costs of sugar beet productivity by macro and microelements, costs associated with the assembly of single added microsurgeons, cost of microwave system, expenditure on production of products according to options, etc., the experimental results of the experimental studies carried out in different regions of the country are proven by the fact that the use of microcirculation by drop irrigation method is well-aerated in the soil zone of the root system of plants, where normal biological activity of beneficial microorganisms is provided, it is ensured that the required amount of continuous fertilizer in the formulation of the solution provides optimal nutrient, water, and air regimes in the soil, which, in turn, promotes biological and physical improvement of the plant and, consequently, increases productivity and improves product quality.
\end{abstract}

Key words: Amortization, base option, cost rate, economic performance indicators, investment, irrigation, microcirculation, surface wash, technical.

\section{INTRODUCTION}

The microcurrents are one of the most important sequences of the hydrochloric beryllium hydrogenation. Microscopic, including its major species, is a substitute for the watercolor zsulun, which is supposed to be submerged in the South. In 1918, Simmer Blass and his twin daughters were able to convey ACL to the University of Clermont. The Lakynian Baalidine was not given up (so-called plastic bottlenecks). In 1948, Sekko Blass incomplete drug injection due to the biochemistry of chrysophilic. One of the worst strikers, Simya Blass, was Israel's successor to the 1962 Waterfall Waterworks. In 1968, the southernmost region of South Kyrgyzstan has an epicenter of 800 headquarters.

Then, in a few countries, the temperature of the tsunami has dropped. In the 1970 s alone, irrigated

\section{Address for correspondence:}

Z. H. Aliyev

E-mail: Volqa_5@mail.ru farms were rising to 4.2 million degrees in the 1970 s, in 1975 , there were 110,000 headwaters, and 1980 s in the south of the country for 350,000 ha. This steam boom absorbs ACS at $172 \mathrm{mAh} .{ }^{[1-3]}$

The increase in the production of agricultural crops is one of the priorities of agrarian production in Azerbaijan, both for meeting domestic needs and for exporting them. In solving this problem, a significant role belongs to the regions, the natural and climatic and economic conditions of which are favorable for the successful development of irrigated agriculture.

And taking into account the long traditions and high level of professional training of agricultural specialists, the experience of the population, and the transfer of this direction to the private sector, we can safely assert not only the development of mountain-irrigated agriculture in Azerbaijan in the coming years but also its revival based on the introduction of high-performance modern technologies irrigation, as pulsed sprinkling, micro- 
irrigation, pulsed sprinkling of self-oscillating action, combined irrigation, impulse rain selfoscillating action with automated control, and a number of others.

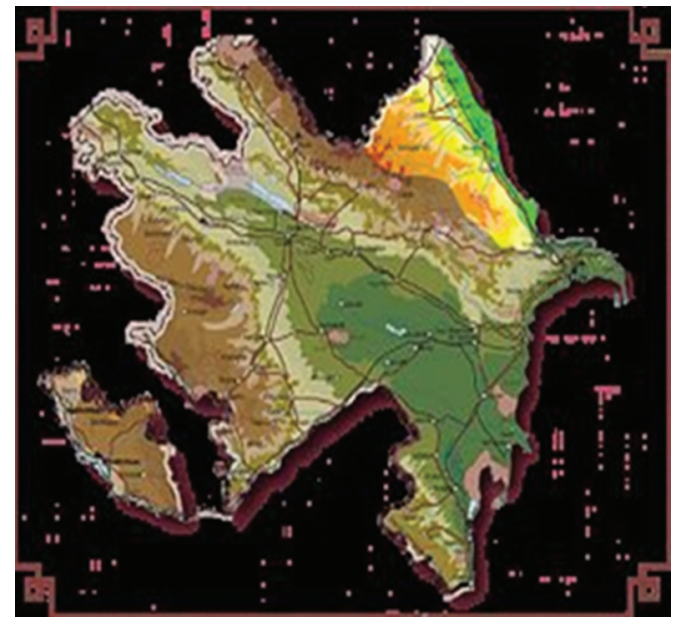

Taking into account that the territory of Azerbaijan, which is the most favorable for cultivation of various types of crops by natural conditions, is located in zones of unstable and insufficient moisture, the intensification of fruit growing is possible only with the use of lowintensity irrigation systems. The necessity of using this kind of irrigation is also due to the increased demand of agricultural crops for moisture supply.

\section{COURSE OF RESEARCH AND DISCUSSION OF RESULTS:}

At the research facilities on the territory of the Republic, irrigation with micro-irrigation was carried out on medium and large slopes with a deep level of groundwater in the period of 2005-2011.

At the same time, the cultivation of fruit trees with an irrigation device of the IDAD type and a micro-diver of various modifications was studied in the experimental site of the OEB of the Institute of Erosion and Irrigation of ANAS in the village of Malakh of the Shemakha district with an area of 4.82 ha, in the period of 2006-2010, in the Guba RWC in the Shahdag foothills on an area of 2.8 ha, in the period of 2004-2006, the work was also carried out in the Ganja district of the PAC in the village of Ganja, Bagmanly, with an area of 4.45 ha, in the period of 2007-2011. ${ }^{[4,-7]}$

Also, on irrigated light chestnut soils with a maximum moisture capacity of $3000-3100 \mathrm{~m}^{3} / \mathrm{ha}$ and on deep seated serozems groundwater in the
Alazansky valley of the Zakatala district in the period of 2004-2006. Forty-nine irrigations (500 $650 \mathrm{~m}^{3} / \mathrm{ha}$ ) with an irrigation rate of $1890 \mathrm{~m}^{3} / \mathrm{ha}$ were carried out. Only the upper layer of the soil $(28-30 \mathrm{~cm})$ was moistened.

In the middle of July, the moisture content of the soil in the $30 \mathrm{~cm}$ layer decreased to $40 \%$ (from PPW) and in early September to $40-60 \%$ (in the meter layer), which led to drying and a decrease in maize yield for silage and winter wheat. At the control plot (five irrigation on furrows with an irrigation rate of about $16,000 \mathrm{~m}^{3} / \mathrm{ha}$ ), the humidity was $80-100 \%$ of protection of plant varieties (PPV).

As a result of the research, it was recommended to optimize the irrigation norm, the number of irrigation, and the reduction of interirrigation periods; it was pointed out that it was expedient to use sprinkling with the use of the design developed by the author for the various modifications of microaraners tested at the experimental site, where watering along the furrows proved to be difficult and in general impossible at all.

At the Institute of Erosion and Irrigation of ANAS with the participation of the author, experiments on irrigation with the IDAD apparatus and other modifications of the micro-irrigation irrigation technique of various types of agricultural crops on newly developed rainfed lands have been continued. On the example of the objects of research on which the experiments on the problems of the development of mountain-irrigated agriculture in the zones of Guba-Khachmas, Ganja-Gazakh, Garabagh, Upper Shirvan, ShekiZagatala, and other regions of the republic were laid. It should be noted that in the zones of the experiment, the soils are overlying, felling, loam (sierozem), and so on. Land with different soil characteristics, and in all these zones of the experiment, the groundwater table is deep. With all this, it was planned to increase the density of plants and not to conduct inter-row treatments. From the experimental sites on the territory of the research objects, from which a "registration site" with more amicable shoots was isolated, divided into plots located at the site of the Shemakha OEB Institute of Erosion and Irrigation of ANAS in the village of Malham and Guba RAN in the foothills of Shahdag in the Guba area with a total area of 4.82 ha [Table 1]. 
During the vegetation period, 94 irrigation operations were carried out with an estimated irrigation rate of $4590 \mathrm{~m}^{3} /$ ha, which did not ensure normal soaking of the soil.

The height of the fruit tree plants (about $5.0 \mathrm{~m}$ ) and the area along the humidification contour $\left(8-10 \mathrm{~m}^{2}\right)$ is less than in furrow irrigation. The root system spreads in the depth of the layer $2.0-2.5 \mathrm{~m}$ and with furrow irrigation in the depth of the layer more than $3.0 \mathrm{~m}$.

Moistening of such a small area was uneven and yields in more moistened areas in apple orchards in the Guba region amounted to 210.9 centners/ha and 189 centners per ha at the Ganja RCAN, and on drained, respectively, 147.3 and 113.9 centner/ha.

The absence of cultivation of crops under the narrowed between rows led to a strong compaction of the soil and a decrease in water permeability, which increased the surface runoff during irrigation. The increase in the density of standing did not have a noticeable effect on the suppression of weeds. The development and growth of fruit (apple, pear, peach, persimmon, etc.) passed at a relative soil moisture of $20-40 \%$, soaking did not exceed $35 \mathrm{~cm}$. Originally in 2007-2008, to select the object of the study, we chose an experimental site in the OEB of the Erosion and Irrigation Institute of ANAS in the village of Malham of the Shemakha district, on the OEP of the Guba RUCN in the Guba district on the Shahdag foothills with a common.

With an area of 2.8 ha and on the EIA of Gyandja RUCN in the village B/Bagmanli with an area of 4.45 ha. It has been proven by the results of numerous experiments and researches, when choosing the right crop irrigation technology, it is imperative that we study the agro-soil, natural-economic, geographical relief of the territory, and the degree of natural moisture and other characteristics based on the monitoring of multi-year data on the object of research, which we should study. In the example of the Shamakhi region specified that, where it was decided to set up experiments in the period 2007-

Table 1: Density of standing plants, between rows

\begin{tabular}{lcc}
\hline Variants width & $\begin{array}{c}\text { Between rows, } \\
\mathbf{~ m}\end{array}$ & $\begin{array}{c}\text { Density of standing } \\
\text { plants, thousand pieces/ha }\end{array}$ \\
\hline I & $4.5-5.0$ & 198 \\
II & $2.8-3.0$ & 280 \\
III & $2.2-2.5$ & 383 \\
\hline
\end{tabular}

2009 for which it is shown in the table! waterphysical and agro-chemical properties of the soil of the object of research, experiments that were carried out on the territory of the village Malham of the Shamakhi region.. The results of our analysis showed that on the territory of the Shamakhi region widespread mainly degraded mountain brownishbrown soils are mainly widespread.

The climatic and climatic conditions of the Aral rocks are favorable for the cultivation of algae. Lacquer and high-quality products are also available due to climate change and agricultural technology, taking into account the climatic conditions and biological characteristics of the plant. During their studies, they studied the peculiarities of the local agrarian nature, the land plot, the armagic boy and the development of dynamics, macro- and microelement droppers applied using micro-irrigation technologies, drip irrigation, and predominantly traditional irrigation dominant technology that allows the issuance of mineral fertilizers along with irrigation water for local nutrition of plants. As a result of the research, the most effective yields and indicators of macro- and microclimate used in sewage treatment plants [Table 2].

Macro and microelements together with irrigation water are provided as follows.

I. In the case of non-profit

- Restless (without fertilizer)

- N120P120K90-fnn

- Fund + B3Zn3.

Ii. Do not drain

- Restless (without fertilizer)

- N120P120K90-fnn

- Fund + B3Zn3.

II. Do not waste

- Restless (without fertilizer)

- N120P120K90-fnn

- Fund + B3Zn3.

Each visitor has three dishes.

The soils of these massifs are medium thick (30$40 \mathrm{~cm}$ ), with slopes $>-0.02-0.025$. Carrying out watering on the furrows is difficult, because of the complex terrain. Therefore, it was planned to sprinkle with small norms, using micro-razors of various modifications.

Water supply for irrigation in these areas (with a total area of more than 8 ha) was carried out from hydrants installed through 85,120 , and $200 \mathrm{~m}$ on 
Aliyev: Evaluation of the use of the microwave system

Table 2: Conditions for microregulation of vehicles of irrigation systems in the territory objects study

\begin{tabular}{|c|c|c|c|}
\hline Indicators of the & “Guba RATSN" & "Terter RATSN" & "Ganja RATS" \\
\hline Type of soil & Loess-like loams & Pebble gravel (low power) & Loess-like loam \\
\hline Limit field moisture, $\mathrm{m}^{3} / \mathrm{ha}(\mathrm{PPV}) \ldots$ & 2970 & & 2500 \\
\hline Water permeability in the $1^{\text {st }} \mathrm{h}, \mathrm{m} / \mathrm{h}$ & & 1100 & 0.04 \\
\hline Slopes & $0.03-0.05$ & 0.06 & $0.004-0.007$ \\
\hline Depth of occurrence of groundwater, $\mathrm{m}$ & 0.001 & $0.02-0.03$ & $2.5-7.10$ \\
\hline $\begin{array}{l}\text { Mineralization. G/1 } \\
\text { Surface discharge from irrigated area, \% }\end{array}$ & $\begin{array}{c}0.0001 \\
1-4\end{array}$ & $\begin{array}{l}\text { More than } \\
10\end{array}$ & $13-14$ \\
\hline Wet charge irrigation & & & As much as possible \\
\hline Watering, $\mathrm{m}^{3} / \mathrm{ha}$ & $3-10$ & Up to 30 & $10-20$ \\
\hline Productivity, q/ha & $\begin{array}{c}\text { No } \\
\text { Carried out in winter } \\
2500-3000 \\
30-40\end{array}$ & $\begin{array}{l}\text { Conduct inappropriate } \\
\qquad 5-10\end{array}$ & $\begin{array}{l}\text { Held in the late-sen.perd } \\
1500 \\
15-20\end{array}$ \\
\hline
\end{tabular}

the corresponding transport pipelines, into open sprinklers (at a rate of $60,80,100$, and $120 \mathrm{l} / \mathrm{s}$ ), cut perpendicular to it. It was found that at irrigation rates of $300-420 \mathrm{~m}^{3} /$ ha, the soil is soaked to insignificant depth $(20--30$, sometimes up to $40 \mathrm{~cm})$. The low absorption rate of the upper soil layer and large slopes provided a significant surface discharge (30\%), increasing from irrigation to irrigation. The addition of moisture in the soil was only $100-300 \mathrm{~m}^{3} / \mathrm{ha}$. Small irrigation rates require private watering (after 5-6 days). The supply of large irrigation norms (600-700 $\mathrm{m}^{3} / \mathrm{ha}$ and more) is difficult due to a mismatch in the intensity of the rain $(2-3 \mathrm{~mm} / \mathrm{min})$ and the rate of water absorption into the soil. Large drops of rain destroy the structure of the soil, and the upper $2-3 \mathrm{~cm}$ is swollen; the absorption rate decreases, resulting in a surface discharge. Then, an experimental site for micro-irrigation for watering vineyards, soybeans, sugar beet, corn for silage, and fruit trees was organized, in the territory of Ganja RACC of the village. B/Bagmanli with an area of 4.1 ha and AIA of the Agricultural Research Institute of the Terter region with an area of 1.5 ha.

The soils of the site (with a total area of more than $30 \mathrm{ha}$ ) are average loam, gradients of 0.005 [Figures 1-3]. And so in 2007-2009, irrigation norm was performed with irrigation norm of 3700-4200 $\mathrm{m}^{3} /$ ha (irrigation norms from 350 to $550 \mathrm{~m}^{3} / \mathrm{ha}$ ). Moisture in the $60 \mathrm{~cm}$ layer did not drop below $60 \%$ of the PPV, and after irrigation, it was $80-90 \%$ of the PPV. Soaking of the soil was no more than 30 $50 \mathrm{~cm}$ (most of the water in the $20 \mathrm{~cm}$ layer).

The yield for soybean production was $14-17 \mathrm{c} / \mathrm{ha}$. In 2010, late spring water recharge was performed on the upper part of the site (with an area of $0.6 \mathrm{ha}$ ) (the groundwater level here was deep, and the rest of the site varied from 2 to $5.5 \mathrm{~m}$ ).

Reserves of moisture in the soil were insufficient to produce shoots, so in mid-May, the reseeding was carried out after the pre-sowing irrigation with the norm of $250-300 \mathrm{~m}^{3} / \mathrm{ha}$.

Where, irrigation was conducted in this period with an irrigation rate of $3800-4200 \mathrm{~m}^{3} / \mathrm{ha}$. Further, all this work was expanded in the Samukhian area of corn on the trees and mulberry trees, in the Shamakhi district in vineyards, in the Guba district of fruit gardens, and Khachmas district of vegetable crops (cabbage, eggplant). Studies on sprinkling in this facility have shown that the rainfall in the IDAUD $(3 \mathrm{~mm} / \mathrm{min})$ is greater than the rate of water absorption into the soil of the research object. Therefore, when feeding $500 \mathrm{~m}^{3} / \mathrm{ha}$, puddles and surface discharges were formed at the site.

The discharge was 20-30\%, which led to uneven moistening. At the beginning of vegetation due to timely treatments, the surface discharge decreased (up to $8-10 \%$ ). When the treatment of crops ceased, the discharge again reached 16-17\%.

Soaking of the soil during watering did not exceed $30-60 \mathrm{~cm}$. Greater wetting and better uniform moisture distribution under these conditions is achieved with irrigation rates of more than 300 $400 \mathrm{~m}^{3} /$ ha. At such rates, about $60-70 \%$ of water remains in the upper $(20 \mathrm{~cm})$ layer, and the plants are not completely supplied with moisture. A big drawback with the irrigation of the Idad apparatus in the presence of an irrigation network, impassable for machining mechanisms. It was found out that sprinklers and roads along them occupy $6-8 \%$ of the area; for example, in this case, water losses in 
irrigation systems built in the Guba RRCN were $30-35 \%$ per $1 \mathrm{~km}$ and in Terter AOS $20-25 \%$.

The distribution of water in micro-irrigation according to calculations (according to B.H. Aliyev's method) was as follows [Table 3].

At the same time, the greatest losses occurred in the discharge and evaporation.

Irrigated standards for various soils and slopes, under which the runoff of water begins, where the results of the study are shown in Table 4.

According to Prof. B.H. Aliyev, the surface discharge in the Guba RNCN zone during watering of apple gardens on the territory of the experimental plot is 7-8\% until August, and in August - 20\%, which testifies to the results of the research in the period of 2006-2011.

It should be noted that even according to the results of the studies carried out in the Terter region on small slopes and fertile soils, where fields are leveled annually, even after feeding $350-400 \mathrm{~m}^{3} / \mathrm{ha}$, puddles appear on the surface of the field. When testing the IDAA with deflector nozzles both in the Guba-Khachmaz RADSN and in the Terter AOS (rain intensity $0.7-1.2 \mathrm{~mm} / \mathrm{min}$ ), positionally, the formation of puddles and runoff on medium and heavy soils at irrigational norms of $250-300 \mathrm{~m}^{3} / \mathrm{ha}$. Small irrigation rates (before the formation of runoff) require a large number of irrigation.

Thus, in the Shemakha region, in the experiments carried out by the Shamakhi EIA of the Institute of Erosion and Irrigation of ANAS (4.8 ha) on heavy soils with a deep bedding of groundwater at the same irrigation rate $\left(7000-7500 \mathrm{~m}^{3} / \mathrm{ha}\right)$, the number of irrigations with micro-irrigation (42-53) was significantly larger than in the case of furrows along furrows. ${ }^{[3,8,9]}$ To combat cortex and compaction, it was necessary to sharply increase the number of inter-row treatments (up to 10), which did not completely destroy the crust near the stem. Shallow and uneven soaking of the soil and untimely processing of crops led to a marked reduction in yield during sprinkling.

Production experiments on micro-irrigation were carried out in the Zakatala district. The tests of sprinkler technology such as IDAD, MDP, multiple drug resistance, and developed by us have established that with a deep level of groundwater and a complex relief, the use of IDA, on watering tobacco and corn, apple, etc., is more promising than other dominant traditional (surface) methods of irrigation.

The results of the test revealed that to reduce the intensity of rain on the sprinkling heads of the apparatus, special nozzles-vichrators were mounted for sprinkling up to $40 \mathrm{~m}$ in radius and more than the action and added additional devices for regulating the rain layer, which helped to suppress pressure in the pump discharge port.

All this allowed to reduce the intensity of rain and give irrigation rates of $600-700 \mathrm{~m}^{3} / \mathrm{ha}$ (with a daily

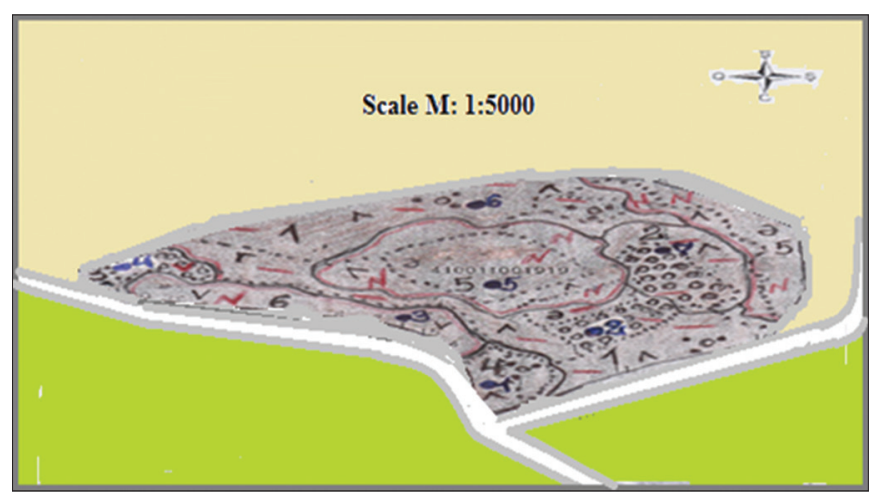

Figure 1: Land plot plan (s) of the area the village Malham of the Shamakhi

Table 3: Water balance during sprinkling in the experimental areas of Terter, Shamakhi, and Ganja RACS

\begin{tabular}{|c|c|c|c|c|c|c|}
\hline \multirow[t]{2}{*}{ Balance sheet items } & \multicolumn{2}{|c|}{ Ganja RATSN } & \multicolumn{2}{|c|}{ Terter RATSN } & \multicolumn{2}{|c|}{ Shamakhi RATSN } \\
\hline & $\mathbf{M}^{3} / \mathbf{h a}$ & $\%$ & $\mathbf{m}^{3} / \mathrm{ha}$ & $\%$ & $\mathbf{m}^{3} / \mathrm{ha}$ & $\%$ \\
\hline Coming & 644 & 100 & 693.7 & 100 & 657.2 & 100 \\
\hline Total & 644 & 100 & 693.7 & 100 & 657.2 & 100 \\
\hline \multicolumn{7}{|l|}{ Including } \\
\hline Filtration into the soil & 16.2 & 2.6 & 55.7 & 8.0 & 49.7 & 22.9 \\
\hline Exact volume ....... & 7.1 & 1.1 & 10.0 & 1.4 & 14.7 & 1.23 \\
\hline \multicolumn{7}{|c|}{ Evaporation when rain drops } \\
\hline Fall to the ground & 81.2 & 12.6 & 88 & 12.7 & 86.3 & 14.1 \\
\hline "Reset from the field & 86.5 & 13.4 & 162 & 23.4 & 183.4 & 197 \\
\hline Left on the field & 453.0 & 70.30 & 378 & 54.5 & 484.8 & 42.07 \\
\hline
\end{tabular}




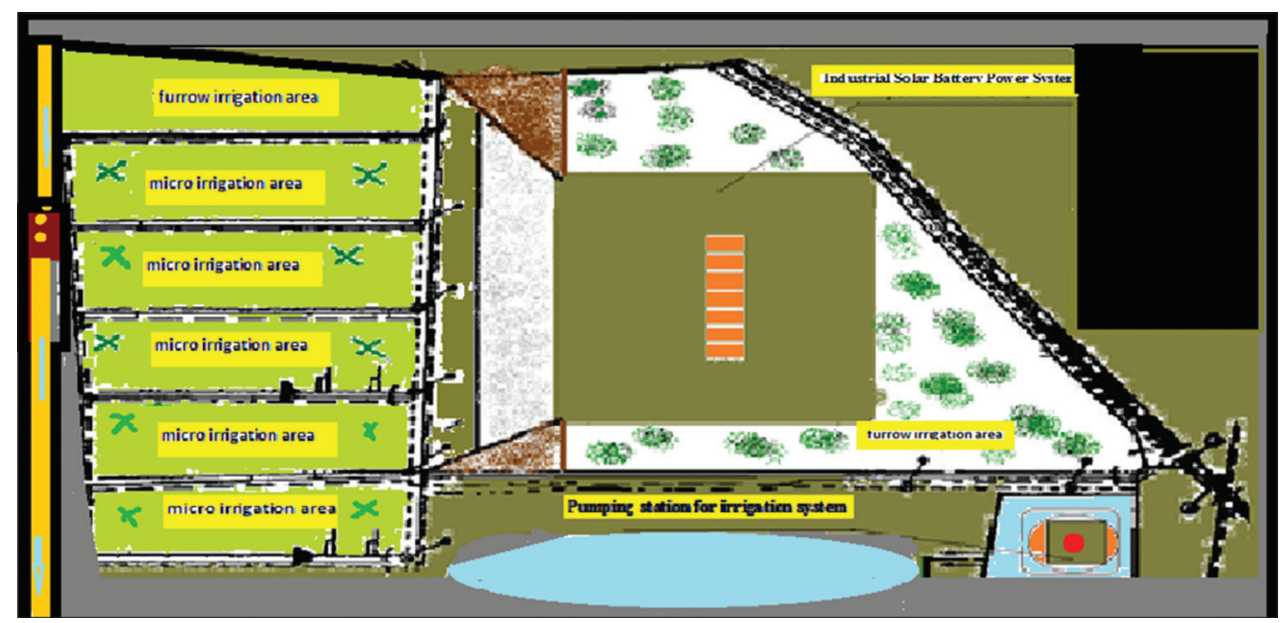

Figure 2: Scheme of the irrigation sprinkling station on the experimental part of the Terter RACS in the Garabagh land in the period of 2006-2010 with the use of the Idad and multiple drug resistance sprinklers

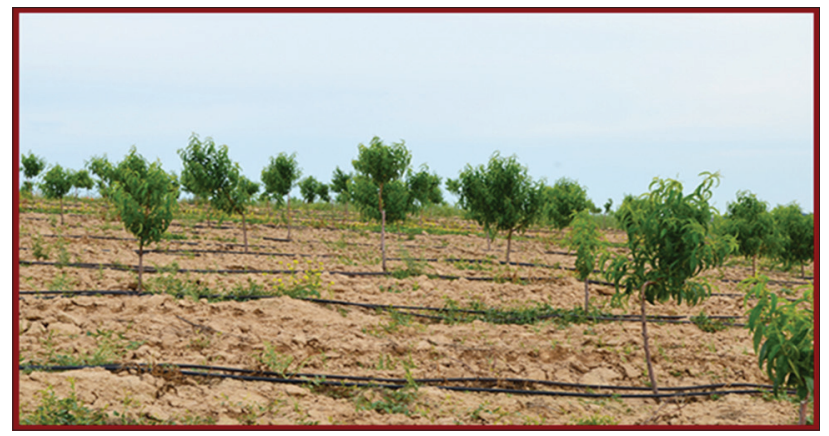

Figure 3: Demonstration of the micro-irrigation regime using drip irrigation of fruit trees in the conditions of the EIA of the Research Institute of Erosion and Irrigation in the Shamakhi district in the village of Malkham

Table 4: Irrigated norms $\left(\mathrm{m}^{3} / \mathrm{ha}\right)$ before the appearance of runoff based on the results of the conducted study in the regions of Guba-Khachmaz and Ganja-Gazakh zone

\begin{tabular}{lccccc}
\hline Soil & \multicolumn{4}{c}{ Slopes } \\
\cline { 2 - 3 } & \multicolumn{2}{c}{$\mathbf{0 . 0 0 0 2}-\mathbf{0 . 0 0 0 5}$} & & $\mathbf{0 . 0 0 2}-\mathbf{0 . 0 0 7}$ \\
\cline { 2 - 3 } \cline { 5 - 6 } & $\begin{array}{c}\text { First } \\
\text { watering }\end{array}$ & $\begin{array}{c}\text { Last } \\
\text { watering }\end{array}$ & & $\begin{array}{c}\text { First } \\
\text { watering }\end{array}$ & $\begin{array}{c}\text { Last } \\
\text { watering }\end{array}$ \\
\hline Sandy loam & 450 & 230 & & 400 & 170 \\
Light loam & 340 & 150 & & 290 & 100 \\
Medium loamy & 290 & 90 & & 170 & 80 \\
\hline
\end{tabular}

mode of operation) without significant surface discharge and soil erosion. Such measures can reduce run-off, but this reduces labor productivity in watering. However, it is also difficult to equip sprinklers with a higher water delivery rate in the range of $800-1000 \mathrm{~m}^{3} / \mathrm{ha}$, where significant planning work is required.

The proposed nozzles installed on the ISAD sprinkler have a relatively low rain intensity, which is explained by the desire to create a microclimate over plants with low water consumption, with limited geometry of the irrigated area.

Experience proves that with increasing capture width, it would be possible to reduce the intensity of rain while retaining labor productivity.

The experimental work carried out by us at the above-mentioned research facilities in Terter, Zagatala, and Ganja on irrigating soybeans, sugar beet, maize, and tobacco makes it possible to give an approximate average rain intensity $(\mathrm{mm} / \mathrm{min})$ at irrigation rates of $300-500 \mathrm{~m}^{3} / \mathrm{ha}$, depending on the soils: Sandy -0.30 .4 , light loamy -0.20 .3 , and medium and heavy loam -0.1 0.2. Apparently, a wide production check of this irrigation technology, taking into account the recommended rain intensity, will allow us to clarify the technical and economic indicators and the conditions for the application of micro-irrigation.

\section{CONCLUSIONS}

The analysis has shown that irrigation with microirrigation can also find its spread in conditions of close lying of non-saline groundwater.

At a high level of groundwater, high yields of agricultural crops can be achieved, however, technical and economic indicators at the given level of the development of sprinkling equipment in the presence of socioeconomic conditions of life of farming and other farms of the republic are less favorable than surface furrow irrigation.

Further, improvement of sprinkler systems with higher technical and economic indicators, possibly, 
will allow to expand irrigation area of microirrigation in conditions of mountain-irrigated agriculture in Azerbaijan. For this purpose, in the future, micro-irrigation systems of the type IDAD and others proposed for serial production were not tested in the republic for any more (except for research objects) for sprinkling.

\section{REFERENCES}

1. Aliyev ZH, Aliyev BH. Impulslo Su Burakhyo. Patent No. P 20020196, Baky; 2002.

2. Aliyev ZH, Aliyev BH. Impulslu Suburaxıc1. Patent No. I. 20000152.

3. Aliev BH, Aliev ZH. Irrigation Techniques for Farmers and Peasant Farms in Azerbaijan/Monograph. Azerneshr: Publishing House Baku; 1998. p. 113.

4. Aliyev ZH, Aliyev BH, Nuriev CS. Asta Yağışyağdıran Qurğular Systems. Patent No. R. 990100 Baka; 1999.
5. Aliyev ZH. Suvarma Sistemlərinin Optimallaşdırilması. Patent No. I. 99001624.

6. Aliev ZH. Development and Implementation of A PulseSprinkling Device for Auto Oscillatory Action in the Mountainous and Foothill Region of Azerbaijan: Abstract of the Dissertation. Baku: Candidate of Agricultural Sciences; 2003.

7. Aliyev ZH. A Research Report on the Model-Experimental Study of Runoff and Runoff from Rainwater Using Various Soil Protection Techniques on Winter Pastures with Dissected Relief of the Southeastern Part of the Greater Caucasus. Baku: Manuscript of the Research Institute of Erosion and Irrigation; 2004. p. 76.

8. Aliev BH, Aliyev ZH. Zoning of the Territory of the Republic of Azerbaijan for the Selection of Progressive Irrigation Technology. Monograph, Baku: Ziyaya Publishing House; 2001. p. 297.

9. Aliev $\mathrm{BH}$, Aliyev $\mathrm{ZH}$. Irrigated Agriculture in the Mountain and Foothill Regions of Azerbaijan. Baku: Monograph Publishing house Ziya-Nurlan EPP LLC; 2003. p. 330. 